\title{
Age distribution and outcomes in patients undergoing breast cancer resection in Saudi Arabia
}

\author{
A single-institute study
}

Balqis Alabdulkarim, MBBS, MSc, Mazen Hassanain, FACS PhD, Areej Bokhari, MD, Abdulaziz AlSaif, FRCSI, FBES, Hana Alkarji, MBBS.

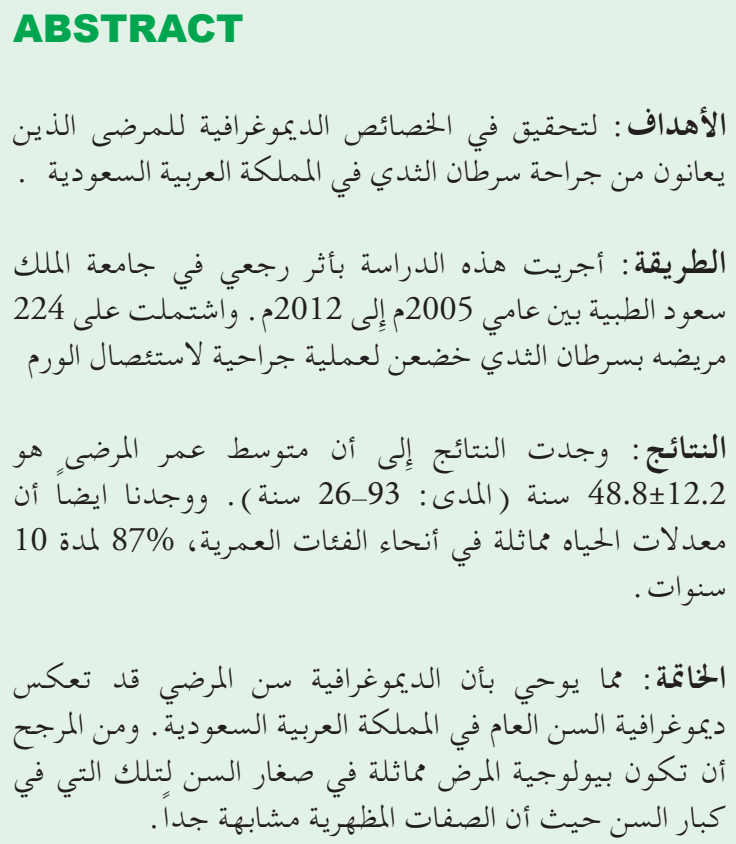

Objectives: In response to rising incidence and mortality we aimed to investigate the demographic characteristics of patients with operative breast cancer in our region.

Methods: We performed a retrospective study of 224 patients who underwent surgery for breast cancer at King Saud University Medical City, Riyadh, Kingdom of Saudi Arabia between 2005 and 2012.

Results: We identified a young population overall with a mean age of $48.8 \pm 12.2$ years (range: $26-93$ years). Survival rate were however similar across all age groups with a 10 -year overall survival of $87 \%$.

Conclusion: Patients in our study were generally younger than those with breast cancer in Western nations. However, unlike Western countries, young age was not associated with worse outcomes.
Saudi Med J 2018; Vol. 39 (5): 464-469

doi: 10.15537/smj.2018.5.21993

From the Epidemiology Department (Alabdulkarim), Lady Davis Institute, Quebec, Canada; from the Surgery Department (Hassanain, Bokhari, AlSaif, Alkarji), King Khalid University Hospital, Riyadh, Kingdom of Saudi Arabia.

Received 14th January 2018. Accepted 28th March 2018.

Address correspondence and reprint request to: Dr. Mazen Hassanain, Surgery Department, King Khalid University Hospital, Riyadh, Kingdom of Saudi Arabia. E-mail: mhassanain@me.com

ORCID ID: http://orcid.org/0000-0002-2441-5142

B reast cancer is the most prevalent cancer among women worldwide and the second most common cause of cancer-related deaths after lung cancer. ${ }^{1}$ In Saudi Arabia, breast cancer accounts for $28.7 \%$ of all newly-diagnosed cancers among women and 15.9\% of diagnosed cancers overall, making it the single most commonly diagnosed cancer in the country. ${ }^{2}$ According to the latest Saudi Cancer Registry report, 1,826 new cases of breast cancer were diagnosed in 2014, with a median age at the time of diagnosis of 50 years. ${ }^{2}$ Saudi Arabia has a unique social structure, with a high rate of consanguineous marriages; thus, a possible distinct epidemiological breast cancer profile has been suggested. Previous local reports have suggested that breast cancer cases in Saudi Arabia are often at a more advanced stage and larger in size. In addition, patients are often younger at presentation compared with other countries. ${ }^{3,4}$ Although the lower average age at diagnosis in Saudi Arabia has been repeatedly attributed to the younger population overall (median age of 28 years), the advanced disease stage observed at diagnosis cannot be attributed to the lack of screening in this age group., 5

Late onset of cancer has been associated with failures in the tumor suppressor mechanisms that accompany the aging process. On the other hand, 
early onset is commonly thought to be caused by an inherited predisposition or early transforming events in the growing epithelium. ${ }^{7-9}$ Clinical studies of breast cancer patients have demonstrated that tumors in older patients are slow-growing and biologically less aggressive compared with those in younger patients. ${ }^{9}$ Furthermore, favorable prognostic molecular features such as luminal types, identified by positive estrogen receptor (ER) status, are observed more frequently in older patients. ${ }^{7,9}$ Similarly, triple-negative tumors, which constitute a rare subtype, are seen more routinely in younger patients. ${ }^{10,11}$ These tumors have poorer prognosis as they show increased proliferation, high nuclear grade, and overexpression of $\mathrm{p} 53 .{ }^{10}$ Additionally, younger age has been shown to be an independent risk factor for early recurrence and mortality.'

Despite the fact that breast cancer incidence is lower in developing countries, overall prognosis is generally worse, with higher mortality. ${ }^{1}$ This finding cannot be solely attributed to younger age at diagnosis, as previous local studies did not observe survival differences between age groups. ${ }^{12}$ In this study, we examined the demographic characteristics of Saudi Arabian patients with operable breast cancer while comparing stage distribution and overall survival between age groups.

Methods. This study included women who underwent mastectomy, radical mastectomy, or wide local excision with axillary dissection at King Saud University Medical Center (KSUMC), Riyadh, Saudi Arbia between 2005 and 2012. Ethical clearance was obtained through the center's institutional review board (ref\# 17/0017/IRB).

All patients with adenocarcinomas were included; those with benign, phyllodes tumors or premalignant disease were excluded. Demographic and tumor-related data were obtained by review of medical records and entered into a database. Data entry was double-checked for quality assurance. Staging of tumors followed the 7 th edition of the tumor-node-metastasis (TNM) staging classification of the American Joint Committee on Cancer applicable at the time of diagnosis. ${ }^{13}$

Overall survival was calculated from the date of surgery until the date of the last follow-up. Patients were divided according to age of diagnosis into 2 groups; 45 years was set as the cut-off age, which has been

Disclosure. Authors have no conflict of interests, and the work was not supported or funded by any drug company. consistently used in other publications in this region., ${ }^{5,12}$ Survival probabilities were calculated using the KaplanMeier method, and a comparison between the 2 groups was performed using the log-rank test. A $p$-value less than 0.05 was considered statistically significant.

Potential prognostic factors affecting survival were studied, including 1) demographic details such as age, parity, breastfeeding, age at menarche, age at first pregnancy, and oral contraceptive pill use, 2) tumorrelated factors such as tumor size, stage, type, receptor status, and lymph node status, and 3) managementrelated factors such as type of surgery, neoadjuvant or adjuvant chemotherapy, radiotherapy, and hormonal therapy. Univariate analysis was performed using the Wilcoxon test for continuous variables and the Chi-square test for categorical variables. Multivariate analysis was performed using multiple regression analysis for significant variables $(p<0.05)$.

Results. In total, 224 patients with a mean age of $48.8 \pm 12.2$ years (range: $26-93$ years) were included in this study, of which $72.4 \% \quad(n=162)$ were of Saudi nationality. The majority of patients were older than 45 years at the time of diagnosis with $44.6 \%$ below the cut-off age. The mean age at menarche was $13 \pm 1.7$ years (range: 9-19 years) for the entire study population, and $13.3 \pm 1.6$ (range: $11-19$ years) for the younger $(\leq 45$ years) and $12.8 \pm 1.8$ years (range: $9-17$ years) for older ( $>45$ years) age groups. The mean age at menopause was $47.5 \pm 7.1$ years. The mean age at first pregnancy was $22 \pm 4.8$ years (range: $14-34$ years) for the entire study population $(22 \pm 4.4$ for the younger and $22 \pm 5.2$ years in the older age groups). Furthermore, $86.4 \%(n=193)$ of patients had breastfed their offspring for a mean duration of $15.1 \pm 8.5$ months (range: 1 -30 months) for the entire study population $(14.9 \pm 8.9$ months for the younger and $15.3 \pm 8.3$ older groups). The mean duration of oral contraceptive pill use was $6.8 \pm 7$ years (range: 2 months -27 years). (6.4 \pm 5.8 years for the younger and $7.1 \pm 8.1$ older groups). The majority of patients in both age groups were overweight, with an average body mass index (BMI) of 32; only 2 patients were underweight with a BMI of 17 . Personal and family history of cancer was recorded when available, but only a small subset of patients were included in the analysis $(n=80)$. Of these 80 patients, $11 \%(n=9)$ had a personal history of other cancers, and 50\% $(n=40)$ had a family history of cancer, of whom $57.1 \%(n=23)$ had a family history of breast cancer.

Regarding disease characteristics, the majority of patients $(92.6 \%)$ had invasive disease, with an average 
tumor size of $3.4 \pm 2.4 \mathrm{~cm}$ at presentation. There was no significant difference $(p=0.43)$ in tumor size between the 2 groups $(3.6 \pm 2.6$ for the younger and $3.2 \pm 2.3$ $\mathrm{cm}$ older groups). Positive receptor status was associated with smaller primary lesions $(p=0.02)$. Stage II disease at presentation was predominant $(56.1 \%)$. Disease characteristics and patient management are shown in Table 1 with specific age-group data.

Seventy-five patients received neoadjuvant chemotherapy, and most patients had undergone modified radical mastectomy $(59.5 \%, \mathrm{n}=144)$. Almost all patients $(91.9 \%, \mathrm{n}=183)$ received adjuvant chemotherapy with extended hormonal therapy. These characteristics did not differ significantly between patients in the 2 age groups.

The median follow-up period was 53.8 months. Ten-year overall survival was calculated for the entire study population (Figure 1) and each age group (Figure 2). There were no significant differences identified between the 2 groups using the log-rank (Mantel-Cox) test $(p=0.89)$. To avoid skewing of data with overwhelming censored entries, only patients with confirmed death or living status were included in this analysis $(n=80)$. No significant differences were found between the 2 groups ( $p=0.8)$. Recurrence was low ( $<25 \%$ of patients); however, it was observed at a higher rate in the younger group than in the older group $(23.3 \%$ versus $15.7 \%$; $p=0.173$ ). Multivariate analysis of survival in relation to various disease characteristics and therapy received revealed a weak positive correlation between the
Table 1 - Disease characteristics for the entire population and by age group.

\begin{tabular}{|c|c|c|c|}
\hline Variables & $\begin{array}{c}\text { Young group } \\
\mathrm{n}=100 \\
\geq 45 \text { years old } \\
(\%)\end{array}$ & $\begin{array}{c}\text { Old group } \\
\mathrm{n}=124 \\
>45 \text { years old } \\
(\%)\end{array}$ & $\begin{array}{c}\text { Total } \\
\mathrm{n}=224 \\
(\%)\end{array}$ \\
\hline \multicolumn{4}{|l|}{ Stage } \\
\hline I & $14 \quad(14.0)$ & $13(10.7)$ & $27 \quad(12.2)$ \\
\hline II & $53(53.0)$ & $71(58.7)$ & $124 \quad(56.1)$ \\
\hline III & $33 \quad(33.0)$ & $37(30.6)$ & $70 \quad(31.7)$ \\
\hline \multicolumn{4}{|l|}{ Type } \\
\hline In situ & $9 \quad(9.0)$ & $7 \quad(6.0)$ & $(7.4)$ \\
\hline Invasive & $90 \quad(90.9)$ & $110(94.0)$ & $(92.6)$ \\
\hline \multicolumn{4}{|l|}{$B M I$} \\
\hline$<25$ & $16(19.3)$ & $18(18.6)$ & $34 \quad(18.9)$ \\
\hline $25-30$ & $36 \quad(43.4)$ & $33(34.0)$ & (38.3) \\
\hline$>30$ & $31 \quad(37.3)$ & $46(47.4)$ & $(42.8)$ \\
\hline \multicolumn{4}{|c|}{ Positive receptor status } \\
\hline ER & $61 \quad(67.8)$ & $82(71.3)$ & $143(69.7)$ \\
\hline PR & $54 \quad(61.4)$ & $74(64.3)$ & $128 \quad(63.0)$ \\
\hline HER-2 & $49 \quad(62.0)$ & $59(56.2)$ & 108 (58.7) \\
\hline TN & 11 (12.2) & $13(11.2)$ & $24 \quad(11.6)$ \\
\hline \multicolumn{4}{|l|}{ Recurrence } \\
\hline Local & 21 (23.3) & $18(15.8)$ & $(14.2)$ \\
\hline Distant & $2 \quad(2.2)$ & $6 \quad(5.3)$ & (3.9) \\
\hline \multicolumn{4}{|l|}{ Tumor size (cm) } \\
\hline$<2$ & $32 \quad(34.8)$ & $36(30.2)$ & $68 \quad(32.2)$ \\
\hline $2-5$ & $45 \quad(48.9)$ & $71(59.7)$ & $116(55.0)$ \\
\hline$>5$ & $15 \quad(16.3)$ & $12(10.1)$ & $27 \quad(12.8)$ \\
\hline \multicolumn{4}{|l|}{ Type of surgery } \\
\hline WLE & $14 \quad(14.1)$ & $19(13.3)$ & $33(13.6)$ \\
\hline Mastectomy & $21 \quad(21.2)$ & $44(30.7)$ & 65 (26.9) \\
\hline MRM & 64 (64.6) & $80(55.9)$ & $144 \quad(59.5)$ \\
\hline \multicolumn{4}{|l|}{ Chemotherapy } \\
\hline Adjuvant & $83 \quad(96.5)$ & $100(91.7)$ & 183 (91.9) \\
\hline $\begin{array}{r}\text { BMI - body m } \\
\text { receptor, H } \\
\mathrm{TN}-\end{array}$ & $\begin{array}{l}\text { Idex, ER - estro } \\
\text { - human epide } \\
\text { e negative, WL } \\
\text { A - modified ra }\end{array}$ & $\begin{array}{l}\text { en receptor, PR } \\
\text { al growth facto } \\
\text { - wide local exci } \\
\text { cal mastectomy }\end{array}$ & $\begin{array}{l}\text { progesterone } \\
\text { eceptor 2, } \\
\text { on, }\end{array}$ \\
\hline
\end{tabular}

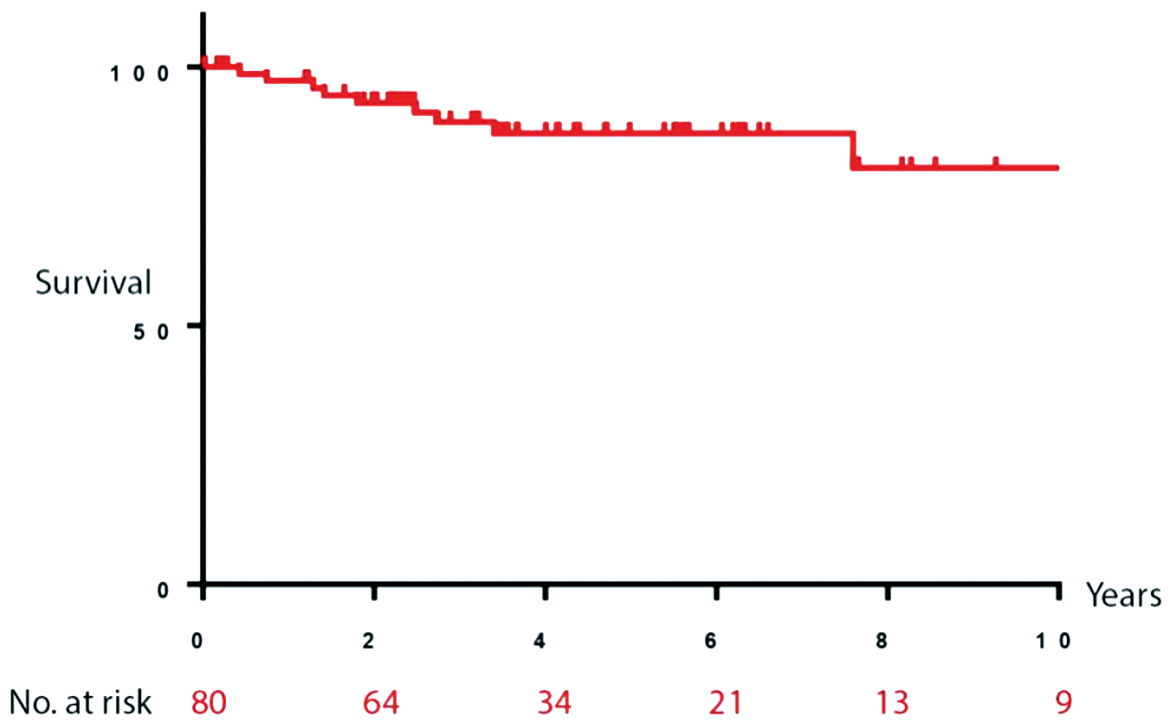

Figure 1 - Ten-year projected overall survival analysis of the study population $(\mathrm{N}=80)$. 


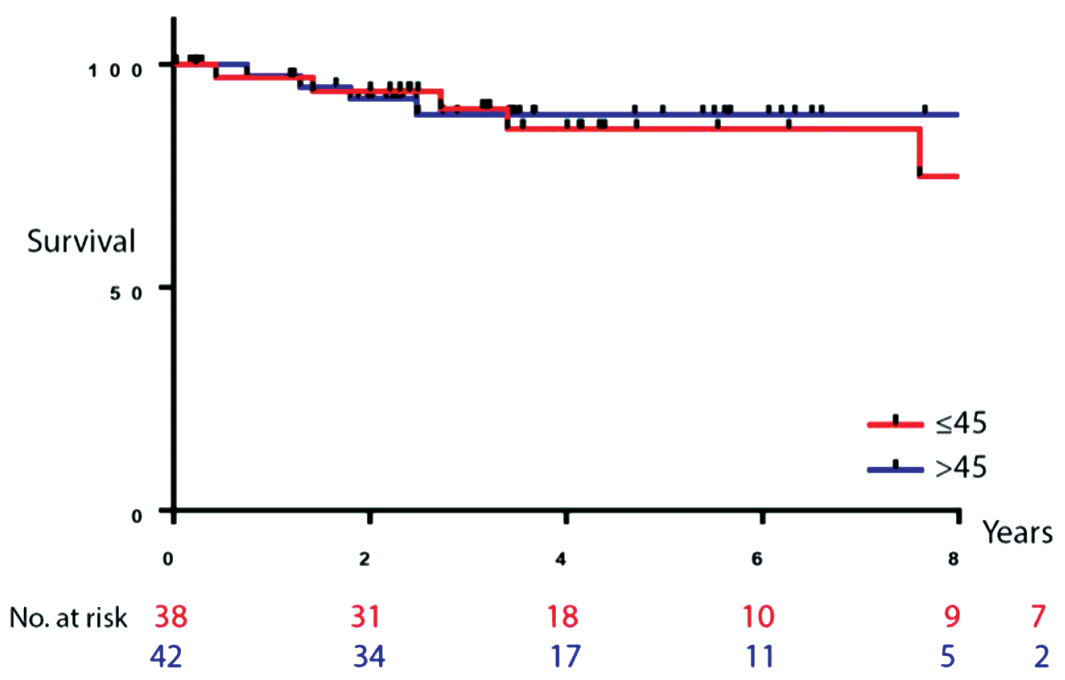

Figure 2 - Overall survival by age group. Kaplan-Meier survival analysis for the 2 age groups: $<45$ years $(n=38)$ and older than $45(n=42)$.

number of neoadjuvant chemotherapy cycles and patient outcome (increased overall survival) $(\mathrm{r}=0.5$, $p=0.0160,95 \%$ confidence interval [CI] 0.1-0.76). This correlation was stronger for patients with stage III disease ( $\mathrm{r}=0.7, p=0.0058,95 \%$ CI 0.33-0.95). Our findings also showed that the younger age group seemed more likely to benefit from neoadjuvant chemotherapy $(\mathrm{r}=0.78, p=0.0073,95 \%$ CI $0.3-0.94)$, while no positive correlation was found for the older group. Furthermore, stage-specific survival for the younger age group showed the highest positive correlation in multivariate analysis $(\mathrm{r}=0.98, p=0.0175,95 \%$ CI 0.38-0.99). Importantly, these findings are limited to the small number of patients included $(\mathrm{n}=22)$.

Discussion. In line with previous publications from our region, we found that the main characteristics of patients with breast cancer were young age at diagnosis and late presentation; however, contrary to what has been reported in Western countries, survival was similar between the younger and older age groups. This supports the notion that the higher incidence of breast cancer in young patients in Saudi Arabia is likely attributable to the young overall demographic of the population (median age of 28 and more than $30 \%$ of the population $<18$ years of age) rather than a biologically different, more aggressive disease. This is further validated by the similarities in disease characteristics between the 2 age groups. Patterns of incidence and mortality rates for breast cancer vary across countries, and are attributable to a combination of demographic, heredity, environmental, and lifestyle factors. ${ }^{14}$ In developing countries, the incidence of breast cancer is increasing, and is becoming more similar to developed countries. Although at present the incidence of breast cancer in developed countries remains higher, mortality is lower. ${ }^{1}$ Several factors, including late presentation, may explain this, as disease stage at diagnosis is strongly associated with patient outcomes. ${ }^{9}$ According to the most recent report of the Surveillance, Epidemiology, and End Results (SEER) program of the National Cancer Institute, the 5-year survival rate for stage I breast cancer was $98.9 \%$, decreasing to $85.2 \%$ for stages II and III and $26.9 \%$ for stage IV breast cancer. ${ }^{15}$ In our study, very few patients presented with early-stage disease $(12 \%, \mathrm{n}=27)$. This may be explained by the absence of successful nationwide screening programs or lack of awareness of screening programs where available. ${ }^{16}$ Current guidelines from the Saudi Center of Evidence-Based Healthcare recommend starting screening with mammography at the age of 40, 5 years younger than the American Cancer Society guidelines. ${ }^{17}$ This recommended age was chosen by the Saudi expert panel based on the increased incidence of breast cancer in patients aged 40-49 years compared with other countries. ${ }^{17,18}$ Although the average age of diagnosis falls within this age group (40-49 years), 20\% of our study population were younger and would have not been diagnosed on screening. Moreover, the application of these guidelines has been limited, as shown by a study that found $92 \%$ of women over 50 have never undergone screening. ${ }^{6}$ There is strong evidence of the benefit of 
screening mammography in countries that implement it well; however, access to such modalities varies across regions. The low percentage of local disease in our study might explain the high proportion of patients (84\%) who received neoadjuvant chemotherapy. Similarly, stage I disease accounts for only a limited number of cases in other studies from our region, with the highest reported percentage being $23 \%$, compared with $60 \%$ in developed countries. ${ }^{5,15}$ Young age at presentation and tumor size might significantly influence the design of national screening programs. According to the current guidelines, patients aged $>40$ years should undergo mammography every 1 or 2 years. However, cancers are more likely to be diagnosed by detection of a palpable mass than by screening. ${ }^{19}$

One reason for the increasing incidence of breast cancer in developing countries could be the aging population. For example, the average patient age in Sweden is 60 years and Mexico 50 years, representing a 10 -year difference. ${ }^{20}$ Our study population had a predominance of young patients $(61.7 \%$ of patients were younger than 50 years), which is expected for this region; the average age in previous studies ranged between 40 and 45 years. 3,5 Adami et al analyzed the relationship between age at diagnosis and relative survival in 57,068 Swedish women. ${ }^{21}$ The best prognosis was identified in patients aged between 45 and 49 years, exceeding the relative survival rate of the patients below 30 years of age by $7.6 \%$ to $12.9 \%$. The worst relative survival rate was observed in patients aged $>75$ years. In fact, relative survival declined after the age of 49 , notably for women aged 50-59 years. The difference in relative survival between patients aged $>75$ years and those aged between 45 and 49 years increased from $8.6 \%$ at 2 years to $12.2 \%, 20.3 \%$, and $27.5 \%$ at 5,10 , and 15 years of follow-up, respectively. The long-term annual breast cancer mortality rate approached $1 \%$ to $2 \%$ for premenopausal ages but exceeded 5\% throughout the period of observation in the oldest age group. ${ }^{21}$

Tumor size and lymph node status are considered the 2 most important prognostic factors in breast cancer. ${ }^{15,22}$ However, only primary tumor size was significantly correlated with recurrence in our study. The average tumor size in our study was $3 \mathrm{~cm}$, which is classified as T2. ${ }^{13}$ Large tumor size may have contributed to the low proportion of stage I disease, as large tumor size increases the likelihood of lymph node invasion. ${ }^{23}$ In another study of 130 patients conducted in our region, the average tumor size was found to be $5.34 \mathrm{~cm} ; 78 \%$ of patients were node positive, and $42 \%$ had 4 or more positive nodes. ${ }^{24}$ Using SEER data as a comparison point, tumor diameter and lymph node status were found to be independent but additive prognostic indicators. The relationship between cases with lymph node involvement and tumor diameter was found to be linear. ${ }^{15}$

Study limitations. Our study is limited by its retrospective nature and the fact that it was conducted at a single center with a small sample size. The favorable survival observed must be attributed to patient selection, as all cases were operable, automatically excluding stage IV disease.

In conclusion, our study is the first to shed light on the peculiar aspects of breast cancer in the Gulf region. No difference was found in the 10-year survival rate across age groups. Our findings should be examined in a larger cohort with the aim of developing countryspecific clinical practice guidelines, which are urgently required. This will address the issues associated with screening programs and the need for local radiation therapy in patients with large breast tumors.

\section{References}

1. Ferlay J, Soerjomataram I, Dikshit R, Eser S, Mathers C, Rebelo $\mathrm{M}$, et al. Cancer incidence and mortality worldwide: sources, methods and major patterns in GLOBOCAN 2012. Int J Cancer 2015; 136: E359-E386.

2. Al-Shahrani Z, Al-Rawaji A, Al-Madouj AN, Hayder MS. Cancer incidence report, Saudi Arabia. 2014. Riyadh (KSA): Saudi Health Council, Saudi Cancer Registry; 2014.

3. Almutlaq BA, Almuazzi RF, Almuhayfir AA, Alfouzan AM, Alshammari BT, AlAnzi HS, et al. Breast cancer in Saudi Arabia and its possible risk factors. J Cancer Policy 2017; 12: 83-89.

4. Albasri A, Hussainy AS, Sundkji I, Alhujaily A. Histopathological features of breast cancer in Al-Madinah region of Saudi Arabia. Saudi Med J 2014; 35: 1489-1493.

5. Alghamdi IG, Hussain, II, Alghamdi MS, El-Sheemy MA. The incidence rate of female breast cancer in Saudi Arabia: an observational descriptive epidemiological analysis of data from Saudi Cancer Registry 2001-2008. Breast Cancer (Dove Med Press) 2013; 5: 103-109.

6. El Bcheraoui C, Basulaiman M, Wilson S, Daoud F, Tuffaha M, AlMazroa MA, et al. Breast cancer screening in Saudi Arabia: free but almost no takers. PLoS One 2015; 10: e0119051.

7. Anderson WF, Pfeiffer RM, Dores GM, Sherman ME. Comparison of age distribution patterns for different histopathologic types of breast carcinoma. Cancer Epidemiol Biomarkers Prev 2006; 15: 1899-1905.

8. Serrano M, Blasco MA. Cancer and ageing: convergent and divergent mechanisms. Nat Rev Mol Cell Biol 2007; 8: 715-722.

9. Brandt J, Garne JP, Tengrup I, Manjer J. Age at diagnosis in relation to survival following breast cancer: a cohort study. World J Surg Oncol 2015; 13: 33.

10. Kumar P, Aggarwal R. An overview of triple-negative breast cancer. Arch Gynecol Obstet 2016; 293: 247-269.

11. Boyle P. Triple-negative breast cancer: epidemiological considerations and recommendations. Ann Oncol 2012; 23 Suppl 6: vi7-vi12. 
12. Ravichandran K, Hamdan NA, Dyab AR. Population based survival of female breast cancer cases in Riyadh Region, Saudi Arabia. Asian Pac J Cancer Prev 2005; 6: 72-76.

13. Edge SB, Compton CC. The American Joint Committee on Cancer: the 7th edition of the AJCC cancer staging manual and the future of TNM. Ann Surg Oncol 2010; 17: 1471-1474.

14. Jönsson B, Wilkin N. Prevention and the economic burden of breast cancer. Chicago (IL): GE Healthcare; 2013.

15. Ries LAG, Melbert D, Krapcho M, Stinchcomb DG, Howlader N, Horner MJ, et al. SEER Cancer Statistics Review, 1975-2005. Bethesda (M): National Cancer Institute; 2008.

16. Abdel-Aziz SB, Amin TT, Al-Gadeeb MB, Alhassar AI, Al-Ramadan A, Al-Helal M, et al. Perceived barriers to breast cancer screening among Saudi women at primary care setting. Asian Pac J Cancer Prev 2017; 18: 2409-2417.

17. Raza D, Rashid M, Redwood-Campbell L, Rouleau K, Berger P. A moral duty: why Canada's cuts to refugee health must be reversed. Can Fam Physician 2012; 58: 728-729.

18. Oeffinger KC, Fontham ET, Etzioni R, Herzig A, Michaelson JS, Shih YC, et al. Breast cancer screening for women at average risk: 2015 Guideline Update From the American Cancer Society. JAMA 2015; 314: 1599-1614.
19. Al Mulhim FA, Syed A, Bagatadah WA, Al Muhanna AF. Breast cancer screening programme: experience from Eastern province, Saudi Arabia. East Mediterr Health J 2015; 21: 111-119.

20. Rodriguez-Cuevas S, Macias CG, Franceschi D, Labastida S. Breast carcinoma presents a decade earlier in Mexican women than in women in the United States or European countries. Cancer 2001; 91: 863-868.

21. Adami HO, Malker B, Holmberg L, Persson I, Stone B. The relation between survival and age at diagnosis in breast cancer. N Engl J Med 1986; 315: 559-563.

22. Fitzpatrick DJ, Lai CS, Parkyn RF, Walters D, Humeniuk V, Walsh DC. Time to breast cancer relapse predicted by primary tumour characteristics, not lymph node involvement. World J Surg 2014; 38: 1668-1675.

23. Soerjomataram I, Louwman MW, Ribot JG, Roukema JA, Coebergh JW. An overview of prognostic factors for long-term survivors of breast cancer. Breast Cancer Res Treat 2008; 107: 309-330.

24. Alnegheimish NA, Alshatwi RA, Alhefdhi RM, Arafah MM, AlRikabi AC, Husain S. Molecular subtypes of breast carcinoma in Saudi Arabia. A retrospective study. Saudi Med J 2016; 37: 506-512. 